\title{
Predictive Value of Class III D Cytological Diagnosis (Munich II, Low and Moderate Dysplasia) and Additional High-risk HPV Testing
}

\author{
Der prädiktive Wert der Gruppe III D und eines zusätzlichen HPV-Tests
}

Author

Affiliation

\section{P. Ziemke}

Gemeinschaftspraxis für Pathologie Dr. Wolf, A. Amirmaki, Dr. Ziemke, Potsdam, Germany

\section{Key words \\ - cervical carcinoma \\ - cervical cytology \\ - class III D \\ - dysplasia \\ - CIN}

\section{Schlüsselwörter}

- Zervixkarzinom

- Zervixzytologie

- Gruppe III D

- Dysplasie

- CIN

\section{received 21.12.2011 revised 7.5.2012 accepted 18.5.2012}

\section{Bibliography}

Dol http://dx.doi.org/ 10.1055/s-0032-1315089 Geburtsh Frauenheilk 2012; 72: 622-629 @ Georg Thieme Verlag KG Stuttgart - New York · ISSN 0016-5751

\section{Correspondence}

Dr. med. Peter Ziemke

Gemeinschaftspraxis für

Pathologie Dr. Wolf,

A. Amirmaki, Dr. Ziemke

Amtsstraße 5 a

14469 Potsdam

gppathopotsdam@t-online.de; peter.ziemke@t-online.de

\section{Abstract \\ $\nabla$}

The validity of cytological diagnostic procedures for the detection of pre- and early cervical cancer stages is limited due to biological conditions, the uncertainty of cell sampling, and the subjective nature of microscopic assessment. Particularly in class III D cases (Munich II) this can lead to a stigmatization of patients and uncertainty with regard to further clinical follow-up and therapy. Prior to carrying out additional investigations such as high-risk HPV testing or the examination of biomarkers, the positive predictive values of patients with a class III D cytological diagnosis need to be assessed in routine practice. To this end, all relevant data from patients from our practice classed as class III D (pap smears) between 2002 and 2008 ( $n=1190 ; 38.2 \%$ histological diagnosis = therapeutic endpoint) and their current HPV status were recorded. Cytology, histology, persistence, age and follow-up were recorded. The database was used for comparative statistical analysis. Overall, the positive predictive value of conventional pap smear for CIN 2+ was calculated to be 32.3\% (mean follow-up: 39.7 months). The following values were calculated for high-risk HPV testing: sensitivity $94.8 \%$, specificity $39 \%$, positive predictive value $42.8 \%$, negative predictive value $94 \%$. The additional information obtained from high-risk HPV testing resulted in a significantly better positive predictive value only in patients older than 40 years. However, there was no evidence for an individual risk stratification approach which would reduce uncertainty in the management of III $\mathrm{D}$ patients.

\section{Zusammenfassung \\ $\nabla$}

Die Aussagekraft zytologischer Diagnosen im Rahmen der Erkennung von Vor- und Frühstufen des Zervixkarzinoms ist durch biologische Gegebenheiten, Unsicherheiten in der Materialerfassung und den subjektiven Charakter der mikroskopischen Beurteilung eingeschränkt. Besonders bei der Gruppe III D der Münchner Nomenklatur II führt dies zur Stigmatisierung von Patientinnen und Unsicherheiten hinsichtlich weiterer Kontroll- und Therapiemaßnahmen. Vor einem sinnvollen Einsatz von Zusatzuntersuchungen (z.B. High-Risk-HPV-Testung, Biomarker) erscheint es nötig, den positiven prädiktiven Wert der Gruppe III D im Routinematerial zu ermitteln. Dazu wurden in der Zeit von 2002 bis 2008 alle Patientinnen unserer Praxis mit der Erstdiagnose III D im Abstrichpräparat und aktuell bekanntem HPVStatus mit allen relevanten Daten $(n=1190,38,2 \%$ histologisch geklärt anlässlich der Therapie mittels Konisation bzw. Biopsie vor Laservaporisation) erfasst und der weitere zytologische bzw. histologische Verlauf auswertbar dokumentiert. Es werden vergleichende Auswertungen unter Einbeziehung von Alter, Verlaufsdauer und Persistenz von III D pro Patientin vorgestellt. Insgesamt errechnet sich für die konventionelle Zytologie ein positiver Prädiktionswert für CIN 2+ von $32,3 \%$ bei einer durchschnittlichen Verlaufsdauer von 39,7 Monaten. Für die High-Risk-HPV-Testung finden sich folgende Werte (\%): Sensitivität 94,8 , Spezifität 39 , positiver prädiktiver Wert 42,8 und negativer prädiktiver Wert 94. Die zusätzliche Information aus dem High-Risk-HPV-Test führt bei Patientinnen der Altersgruppen ab 40 Jahre zu statistisch signifikant besserer positiver Prädiktion. Eine individuelle Risikostratifizierung ist für die III D-Patientinnen insgesamt nicht ableitbar. 


\section{Introduction}

\section{$\nabla$}

Pap smear cytology is carried out during routine gynaecological cancer screening procedures and aims to find pre-cancerous or cancerous lesions. Early detection of such lesions may stop carcinogenesis and prevent the development of carcinomas.

To ensure a good communication between the medical specialties involved in making the diagnosis (cytology, gynaecology, histology), a diagnostic classification was required to describe the levels of pathogenesis. In 1953, the US pathologist Reagan first used the term dysplasia to describe three levels of severity of precancerous lesions which did not fulfil the criteria of carcinoma in situ [1]. This terminology was adopted by the WHO in 1973. The term "cervical intraepithelial neoplasia" (CIN) was proposed in 1968 by Richart to indicate the fact that all pre-cancerous stages of cervical carcinoma were stages of a gradual biological development [2]. For practical reasons and in the interest of accurate morphological diagnosis and therapy, high-grade dysplasia and carcinoma in situ were combined as CIN 3. The Munich classification, based on work by Papanicolaou, was introduced in Germany in 1976 and modified in 1990. The Munich classification aimed to assign cytological findings to histological diagnoses [3]. Cells showing low-grade and/or moderate dysplasia were classified as III D, and cytological assessment and colposcopy was recommended in such cases. Surgical therapy was and is always recommended if there is any evidence of high-grade dysplasia and/or a carcinoma in situ (Group IVa). The Bethesda system, first published in the USA in 1988 and subsequently modified in 1992 and 2001, differentiates between low-grade (indicating an HPV infection, CIN 1, slight dysplasia) and high-grade (CIN 2 and 3, moderate and severe dysplasia, carcinoma in situ) intraepithelial lesions; clinical therapy is indicated even for moderate cytomorphological changes.

In gynaecological screening for pre- and early stages of cervical cancer, low-grade and moderate dysplasias (III D) are the most common cytological lesions with an incidence of around $60 \%$. The cytomorphology of III D lesions does not permit any individual prognosis with regard to either their spontaneous regression or their development into a CIN 3 or a cervical carcinoma. The methodological limitations of cell sampling are well known. Subsequent histological investigations often lead to findings of higher grade lesions [4]. If these higher grade lesions persist, therapeutic procedures are indicated despite the diagnostic uncertainty, to prevent the patient from being placed at risk $[5,6]$.

A cytological III D diagnosis often involves a misunderstanding between all persons involved:

In cytology, the investigating pathologists are well aware of the subjective nature of the microscopic assessment of atypical cells and their morphological differentiation. It is also well known that the patient may have higher grade, squamous intraepithelial lesions not present in the investigated sampled cells, which limits the validity of the cytological diagnosis of low-grade or moderate dysplasia.

If the cytological findings are classified as III D, the gynaecologist attending the patient is obliged to take further steps but, because of the uncertainty described above, will not consider curative therapy to be necessary. When the patient is informed of the pathological findings, this information is usually given with the qualification that the findings are probably harmless. This will be followed by long-term or short-term follow-up investigations or additional therapeutic procedures, depending on the results of colposcopy and of other investigations.
The patient is generally taken by surprise when she is informed of the III D cytological findings, a diagnosis which may or may not be comprehensible to her. She may have undergone regular screening for years and has now, unexpectedly, become "ill" or has suddenly become aware of the risk of cancer. In this situation, in addition to the patient's psyche and level of education, the physician's understanding of the pathogenesis and his or her capacity to communicate this adequately to the patient play an extremely important role.

In summary, it must be noted that the cytological diagnosis of III $D$ at all three levels of involvement is extremely subjective. There is always a risk of under- or over-reaction and thus of under- or over-treatment with all the negative consequences this entails for the patient [7].

Current scientific knowledge about the aetiology and pathogenesis of cervical cancer and its pre-stages means that patients with the cytological diagnosis III D might obtain a clearer individual prognosis with the use of additional investigations including biomarkers [8]. A realistic assessment of the impact of these more expensive methods requires data which would provide information about the diagnostic validity of a cytological class III D diagnosis. There are currently very few publications on this point, and most of them are critical comments on empirical case studies [9]. To date, no randomised studies have been done; however, as the III D classification has been in common use in Germany since several decades, an enormous amount of data is available. The statistical analysis of this data in follow-up studies could offer information about the diagnostic validity of a cytological class III D diagnosis [10-12]. Precise inclusion criteria and correct documentation of cytological and histological follow-up up until the therapeutic endpoint of the study, either through histological diagnosis after surgical therapy or until a pre-defined end of follow-up is reached, are important to ensure that the results of such a study are meaningful.

\section{Aim of the Study \\ $\nabla$}

Aim of this study was to provide statistically relevant information with regard to individual prognosis after cytological III D findings obtained during routine gynaecological screening done in a pathology clinic focussing on gynaecological cytology. The value of additional HPV testing was also assessed.

\section{Material and Methods}

The analysis presented here is based exclusively on anonymised data obtained in our clinic from patients who received a firsttime diagnosis of class III D during screening after a previously unremarkable cytological history of varying duration. With samples submitted by around 30 gynaecologists, the mean annual number of women undergoing cytological screening in the period 1993-2010 was 56293 (min. 34722, max. 67523). A total of 162090 women were investigated in the whole period. The mean annual incidence (prevalence) of patients who were diagnosed for the first time as class III D was $0.68 \%$ (min. 0.41 , max. 1.23). The percentage out of the total group of 162090 women investigated during this period was $4.28 \%$ (6944 patients).

Diagnosis was made based on conventional pap smears using the Munich II classification by a highly experienced pathologist who has been working with cytology samples since 1985 . Additional 


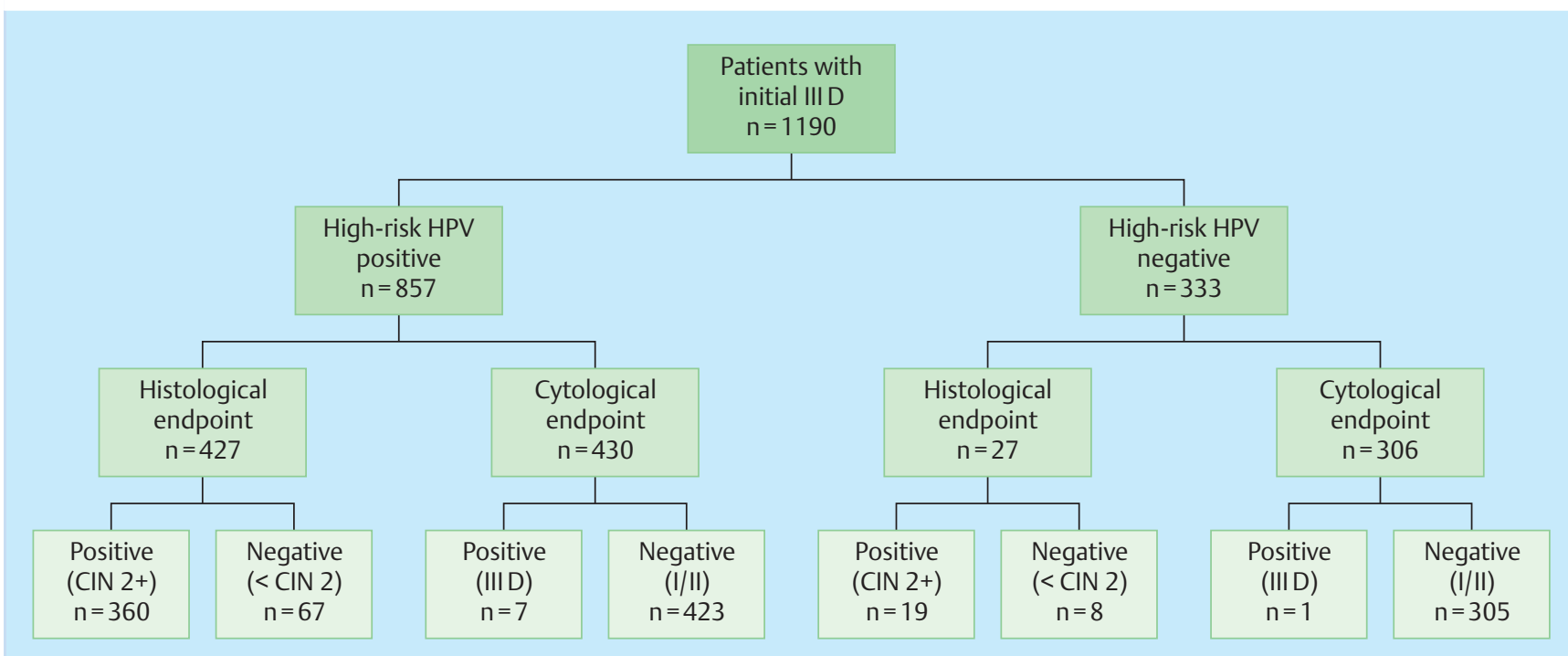

Fig. 1 Development over time at the time of evaluation.

testing to assess the patient's current high-risk HPV status was considered to offer important additional information for analysis. As these clinical data were only available from around 2001 in sufficient quantities and to additionally ensure a sufficiently long follow-up, the acquisition period was from 1 January 2002 up to and including 31 December 2008. The results of high-risk HPV tests were obtained from a number of different regional medical laboratories and testing was usually done by Hybrid Capture (HC II) test.

The following inclusion criteria were used:

- all patients diagnosed as class III D for the first time, and

- known to have a high-risk HPV status

- between 1 January 2002 and 31 December 2008.

Using these criteria, 1190 consecutive patients (mean age: 31.25 years) were included in the study. Based on a total of 3090 patients diagnosed as class III $\mathrm{D}$ for the first time during this period, this corresponds to a sample size of $35.3 \% .857$ patients were high-risk HPV-positive and 333 patients were high-risk HPVnegative. All cytological and histological findings obtained until the end of the follow-up period were recorded in 3-month steps for the follow-up period on an MS-Excel spreadsheet. The end of the follow-up period was characterised by a final histological diagnosis at the time of therapy (cervical conization, cervical biopsy with subsequent laser vaporisation) or cytological investigation at the time of evaluation ( Fig. 1). Histological CIN 2 and 3 findings, squamous cell carcinoma, and cytological class IIID findings (currently 8 cases) were rated as positive follow-up findings. Cytological results were only included if the follow-up period was at least 12 months, and there were at least 2 identical cytological findings at successive follow-ups. This minimum requirement was only met by 38 patients with a cytological follow-up of less than 24 months (range: $12-18$ ). A total of 7758 cytological follow-up investigations were recorded. The selected endpoint for follow-up was based on the consideration that an endpoint of 36 months after inclusion of the last patient into the study would result in an average follow-up period of 39.74 months when no significant numbers of histological diagnoses could be expected any more.
Definition of target criteria:

Positive:

- histologically: CIN 2+

- cytologically: at least 2 identical findings of III D after an interval of at least 12 months

Negative:

- histologically: < CIN 2

- cytologically: at least 2 identical negative findings (class I/II) after at least 12 months

This approach with an average follow-up period of 39.74 months (min. 1, max. 117) allowed all patients to be statistically evaluated and the two methods described above - cytology and high-risk HPV testing - to be compared. In order to be able to make more valid prognoses, the data was differentiated further to compare age groups, the number of cytological III D findings per patient, and the follow-up period. There was, however, a problem in that some patients dropped out of the follow-up earlier than others, changing the structure of the data. Thus, the final histological diagnosis during therapy is usually done on average 17.05 months after the first class III D finding. Later analyses will only include those patients who are still being followed up; thus the proportion of true positive findings at these analysis timepoints available for the statistical evaluation will become increasingly small.

Univariate statistical analysis is an uncomplicated analysis tool which, if the above limitations are taken properly into consideration, can be used to calculate the statistical validity of data [13,14]. The positive predictive value (PPV = true positive/true positive + false positive) is particularly significant for patient management. When evaluating the importance of HPV testing, all measured values of validity can be easily calculated, are meaningful, and can be compared with data from the literature.

Statistical objectivation is possible using the odds ratio $(95 \% \mathrm{CI})$ as a point estimator [15-17]. This can be used to calculate the increased risk of developing a CIN 2+ lesion for an initially high-risk HPV-positive III D patient compared to a high-risk HPV-negative patient. 
Table 1 Statistical validity of cytology and high-risk HPV-testing.

\begin{tabular}{|llllllll} 
Test & $\begin{array}{l}\text { Type of } \\
\text { follow-up }\end{array}$ & Sensitivity & Specificity & $\begin{array}{l}\text { Positive pre- } \\
\text { dictive value }\end{array}$ & $\begin{array}{l}\text { Negative pre- } \\
\text { dictive value }\end{array}$ & $\begin{array}{l}\text { Correctness } \\
\text { Histological } \\
\text { diagnosis (\%) }\end{array}$ \\
\hline hytology & histology & 98.94 & & 83.33 & & 82.60 & 32.18 \\
\hline \\
\hline High-risk HPV & total & histology & 98.97 & & 32.29 & & 38.15 \\
\hline
\end{tabular}

Table 2 Histological diagnoses.

\begin{tabular}{lllllll} 
& Histology & & & & & \\
HPV status & No dysplasia & CIN 1 & CIN 2 & CIN 3 & Squamous cell carcinoma* & Total \\
& $\mathbf{n}(\%)$ & $\mathbf{n}(\%)$ & $\mathbf{n}(\%)$ & $\mathbf{n}(\%)$ & $\mathbf{n}(\%)$ & $\mathbf{n}(\%)$ \\
Positive & $22(5.15)$ & $46(10.77)$ & $173(40.52)$ & $182(42.62)$ & $4(0.94)$ & $427(100)$ \\
\hline Negative & $2(7.41)$ & $6(22.22)$ & $7(25.93)$ & $12(44.44)$ & 0 & $27(100)$ \\
\hline Overall & $24(5.3)$ & $52(11.5)$ & $180(39.6)$ & $194(42.7)$ & $4(0.9)$ & $454(100)$ \\
\hline
\end{tabular}

$* 2 \times$ coincidental finding of an intracervical adenocarcinoma in situ or adenocarcinoma

\section{Results}

Evaluation was based on a comparison of an initial "positive" class III D cytological diagnosis, which indicated the presence of cells with low or moderate dysplasia of the squamous epithelium of the vaginal part of the cervix, and outcomes of simultaneous high-risk HPV testing ("positive" or "negative") at the time of entering the study with the histological or cytological findings at the end of the study. Histological or cytological findings at the end of the study indicating moderate or high-grade dysplasia or squamous cell carcinoma were classified as "positive" and cervical squamous epithelium without dysplasia or neoplasia or only low-grade (CIN 1) dysplasia was classified as "negative". The different inclusion time-points with histological diagnosis as the endpoint resulted in follow-up periods of varying lengths.

The validity of cytological and histological findings compared to the initial diagnosis is shown in 0 Table 1. The positive predictive value of a cytological class III D diagnosis was $32.29 \%$; if this was accompanied by high-risk HPV findings, this value increased to $42.82 \%$.

The histological diagnosis at therapy is an essential source of information about whether the initial findings were true positive ( Table 2). Histological diagnoses were based on 404 conizations, 47 biopsies prior to laser vaporisation, and 3 hysterectomies. A total of $26.2 \%(n=119)$ of these procedures were carried out in our clinic. The high number of histological CIN 3 diagnoses and carcinomas needs to be considered against the background of cytological progression already noted prior to histological diagnosis. For this reason, it is necessary to examine histologically diagnosed cases without or with subsequent cytological progression (class IVa) separately to be able to make a statement about the incidence of histological diagnoses in III D patients. Fig. 2 shows the proportional distribution.

- Table 1 summarizes the data collected during the total followup period with a mean follow-up time of 39.74 months irrespective of the individual follow-up time of the respective patient. While this procedure is common, it only provides general statistical data. More precise information can be obtained through

1. an evaluation of defined follow-up times,

2. comparisons between age-groups, and

3. the examination of patients with a different incidence of class III D findings.

When evaluating specific follow-up times it is important to decide whether initial histological findings will be included when evaluating findings of later follow-ups or whether only the most recent findings will be included in the calculation, e.g. the positive prediction. Fig. 3 shows the differing results for both options. If an evaluation is based on only one year of follow-up, fewer and fewer histologically clarified cases (often "true positive")

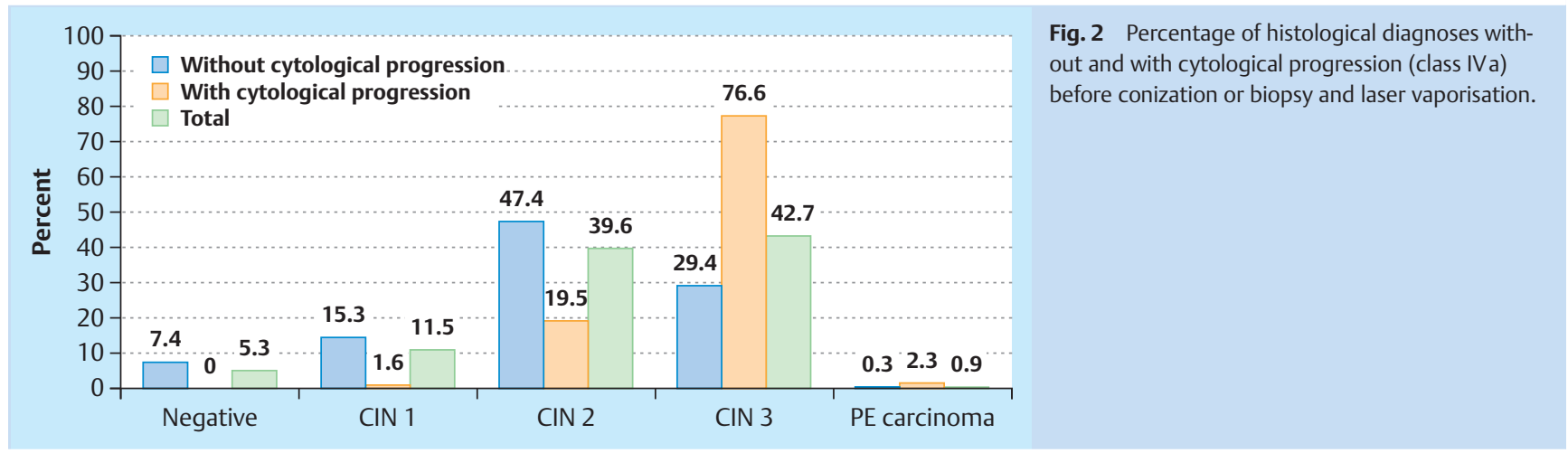




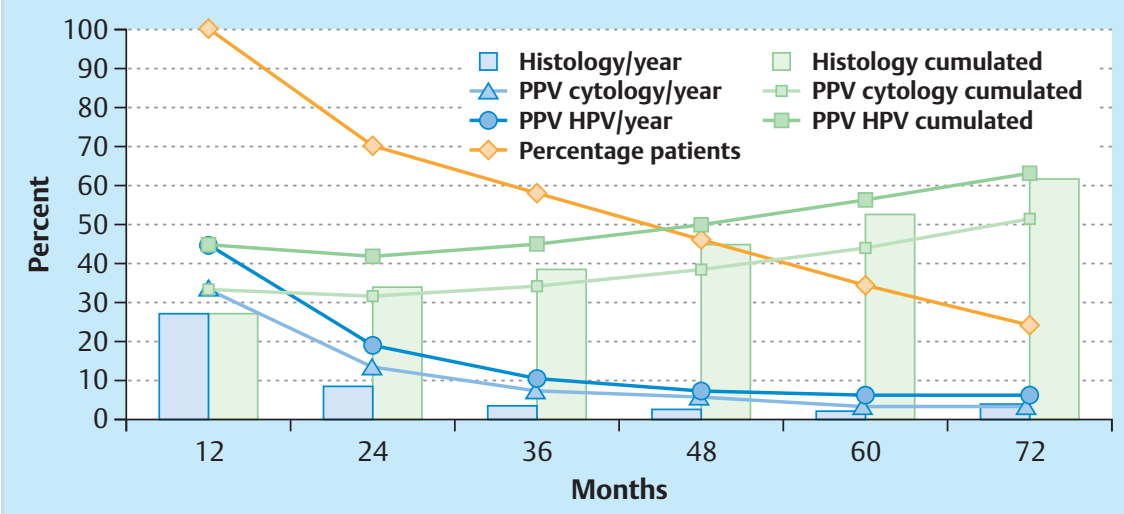

Fig. 3 Positive predictive value and follow-up time with and without cumulation of histological diagnoses.

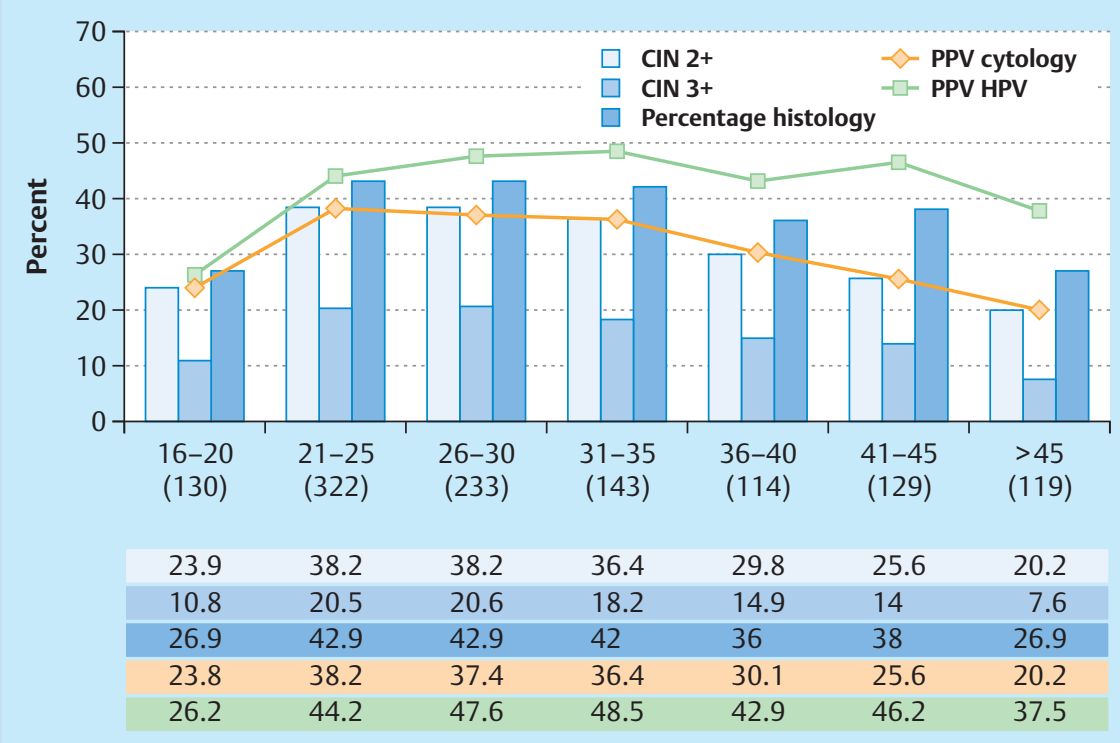

Fig. 4 Positive predictive value of first-time cytological class III D diagnosis with regard to the endpoints CIN 2+ und CIN 3+ (in percent), depending on age.

will present as the total follow-up time increases; the regressive cases (often "false positive") will predominate. The positive predictive value will continually decrease.

- Fig. 4 shows the evaluation according to patient age on entering the study, with the patients grouped into 5-year age groups. A positive prediction (CIN 2+) based on III D cytology was highest for the age group between 21 and 30 years and continually decreased thereafter, while the positive predictive value for highrisk HPV testing was clearly higher for the age group 41-45 and significantly higher for the age group $>45(\mathrm{p}<0.001)$. The incidence of CIN $3+$ in the different age groups was similar.

- Fig. 5 shows the positive predictive value and percentage of cases diagnosed as CIN 2+ or CIN 3+ for patients with varying numbers of cytological III D diagnoses. A continual increase for all parameters and for both methods was detectable when III D findings per patient persisted.

Overall, histological diagnosis resulted in a positive predictive value of $84.31 \%$ for high-risk HPV-positive patients and of $70.37 \%$ for high-risk HPV-negative patients. There were $7 \mathrm{CIN}-2$ and 12 CIN-3 findings among the 27 histologically determined, high-risk HPV-negative cases.

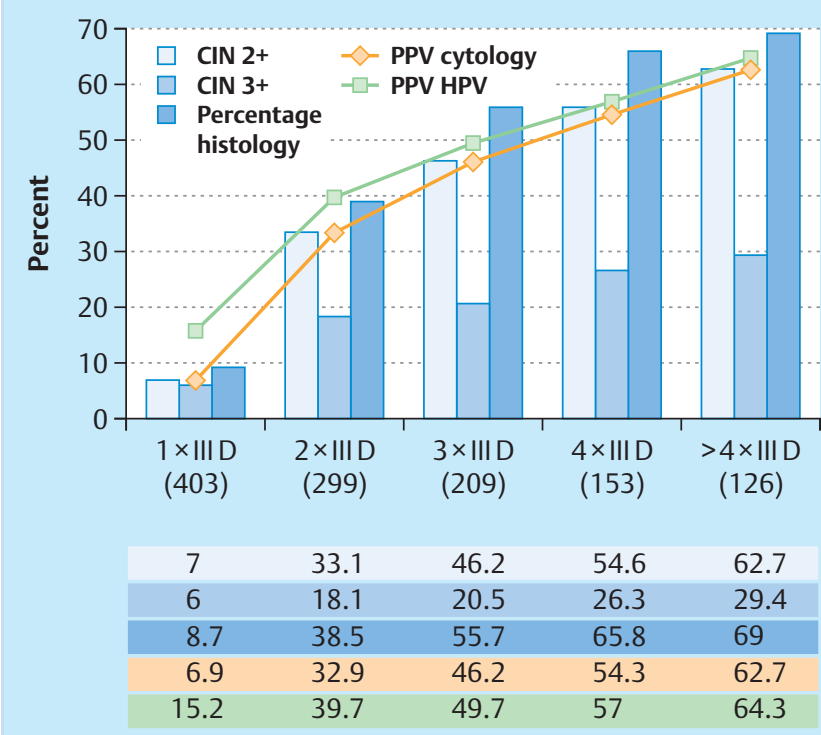

Fig. 5 Positive predictive value of single or multiple III $D$ findings for the development of $\mathrm{CIN} 2+$ or $\mathrm{CIN} 3+$. 


\section{Discussion}

$\nabla$

\section{Cytology}

The figures on the incidence of cytological class IIID diagnoses and the development over time presented here indicate that the usual and required practice of annually collecting and evaluating statistical data to reassess the original cytological diagnosis is inadequate. The biological development of cytologically diagnosed dysplasias of the squamous epithelium of the uterine cervix is often not correct in individual cases and cannot be correctly predicted $[18,19]$. Moreover, at the time of diagnosis it is not possible to state when the detected lesion developed biologically. Only the analysis of cases followed up for a sufficiently long time offers the possibility of making a statement about the statistical - not the individual - probability with regard to clinical outcome [1012 ]. The greatest difficulty is the uncertainty regarding the representativeness of the investigated material, which is clearly one of the reasons for the discontinuous development, with alternate phases of negative and positive cytological findings (28.7\% in the study presented here). This, of course, enormously limits the validity of the usual division into 'regression', 'persistence', and 'progression of findings' for class IIID cytological findings [12, $20,21]$. Currently, no standard exists with regard to the length of time which would classify class III D findings as "persistent". In this study, the longest follow-up of a patient with persistent class III D findings was 63 months; during follow-up a total of 11 III D findings were recorded with short intervals in between where the cytological findings were negative. Subsequently, 7 successive cytology findings were negative (duration of follow-up: 94 months). Histological results of biopsies are considered the "gold standard", but they can only reflect a momentary and localised condition in the uterine cervix and do not offer much information about the longer-term prognostic validity of class III D cytological findings $[22,23]$. Only histological diagnosis (conization, laser vaporisation after biopsy, hysterectomy) can be considered the endpoint for follow-up, as this secondary prevention of cervical cancer interrupts biological progression. The assessment of regression and progression is based on the statistical calculation of the positive predictive value for the comparison of results. Follow-up time plays an important role when comparing results of III D patients. Histological clarification is important for the proper assessment of the original III D cytological diagnosis. On average, such histological clarification during therapy was done after 17.05 months, which is also consistent with regression of an HPV infection over time. Such carcinoma prevention obviously interrupts the continued biological development, limiting the prognostic validity. When follow-up times are much longer, cytological findings will increasingly be negative and the positive predictive value will decrease ( $\bullet$ Fig. 3). A new infection of the patient with high-risk HPV may also be the cause of later positive findings (O Fig. 6). A comparison of individual age groups ( $\odot$ Fig. 4) shows that the predictive value of III D cytological findings is poorer for the older age groups, a finding that is borne out in daily diagnostic experience; this can be explained by the absence of mature cell populations, which limits the possibility of comparing dysplastic and physiological cell populations in cytological samples. Finding dysplastic cells becomes more difficult, and atypical squamous cells of undetermined significance with different cell nuclei shapes and sizes can lead to a false-positive cytological diagnosis. The number of IIID findings per patient ( $\bullet$ Fig. 5) can be taken as an indication of persistence and leads to an almost linear improvement of the positive predictive value

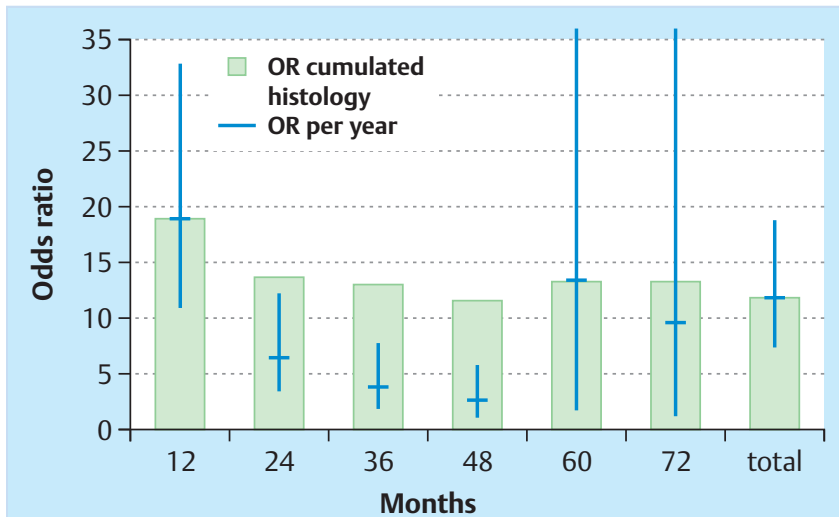

Fig. 6 Odds ratio for initial high-risk HPV test results and follow-up time with and without cumulation of the outcomes of histological diagnoses (95\% Cl).

if the follow-up intervals are sufficiently long, offering a good basis for clinical diagnostic and therapeutic measures. Additional high-risk HPV testing does not significantly improve the prognostic value in this context.

The percentage of CIN 3+ diagnoses in the 454 histological findings was relatively high with $42.8 \%$; however this must be put in perspective. In $28.9 \%$ (131) of cases, the histological diagnosis was made after a previous class IVa cytological diagnosis. The percentage of lesions histologically diagnosed as CIN 3+ after a previous class III D cytological diagnosis was $29.72 \%$, which approximately corresponds to the percentage of all patients of our clinic investigated histologically after class III D cytological findings $(n=1100,25.7 \%)$. In the individual evaluations (age, - Fig. 4; number of III D findings/patient, 0 Fig. 5) the percentage of CIN 3+ diagnoses corresponded approximately to the percentage of CIN 2+ diagnoses. The literature reports an increased number of pre-term births as a late consequence of conization [24, 25]. In this study, conization performed in histologically investigated patients up to the age of 35 years had a high positive predictive value (85.7-87.6\%), with only a few cases where this would have been unnecessary based on the histological diagnosis. The positive predictive value only dropped to around $70 \%$ for patients older than 40 years.

\section{High-risk HPV testing}

To a varying degree in different regions of Germany, the triage of cytologically suspicious or positive findings constitutes an optional part of screening procedures for the early detection of cervical cancer [26,27]. However, overall gynaecological cytology findings are not comparable to the special situation with regard to class III D findings. While cytology generally has a poor sensitivity which can be improved using highly sensitive methods such as HPV testing, class III D findings and HPV testing each have a high sensitivity but a poor specificity or positive predictive value and can theoretically not be used to complement each other [28]. There are only a few studies on the triage class III D cytological findings with HPV testing, and they do not show an improvement in the positive predictive value [4]. Thus, while the Hanover-Tübingen study stated that additional high-risk HPV-testing resulted in a better diagnosis when investigating "abnormal" cytological findings (II W, III D und III), only 61 of these cases were first-time class III D diagnoses, and their study is therefore not 
directly comparable with ours [29]. 72\% of class III D patients investigated in our study were initially high-risk HPV-positive. The overall positive predictive value for this group was $42.56 \%$. Of the initially high-risk HPV-negative patients, $41.4 \%$ showed cytological signs of an HPV infection and/or low-risk HPV positivity; the positive predictive value was only $6.01 \%$. Both groups of patients differed clearly with regard to patient age (mean patient age of the high-risk HPV-positive group: 29.9 years; mean patient age of the high-risk HPV-negative group: 35.1 years) as well as the number of class III D findings per patient (2.84 vs. 1.57 ). The positive predictive values over time allow us to conclude that a negative high-risk HPV result together with first-time III D cytology has a good negative predictive value, particularly with regard to CIN 3 lesions, and justifies a wait-and-see approach. But a look at the patients with a final histological diagnosis puts this into perspective: 19 of the 27 high-risk HPV-negative patients were found to have CIN 2+ lesions, 12 of which were CIN 3 (relative PPV 70.37\%). These positive histological diagnosis were made on average 27.65 months (range: 3-70) after patients were entered in the study. It is quite possible that a new infection may have played a causal role in patients who had a very late positive histological diagnosis. In the follow-up period until the final histological diagnosis, six of the patients were found to be high-risk HPV-positive. Two patients remained HPV-negative at subsequent HPV tests, while test results could not be ascertained for the other patients. The statistical increase of risk for high-risk HPV-positive patients based on the calculation of the odds ratio per follow-up year showed a continuous drop for 48 months, followed by an increase in the last two years of follow-up, while the values remained almost the same for every year of follow-up when all histological diagnoses per follow-up year were included (- Fig. 6). The positive histological diagnoses made in the last two years of follow-up probably do not have a causal connection to the initial high-risk HPV test result. The additional information obtained from a high-risk HPV diagnosis increases the positive predictive value for a patient with first-time class III D cytological findings by about $10 \%$, and this increase is also statistically significant $(p<0.001)$. For the subsequent follow-up of these patients, the better statistical prognosis at this time-point and later on does not translate into any practical individual curative therapeutic approach. When examining all patients who were subsequently cytologically or histologically negative, only $39 \%$ had negative high-risk HPV test results at the time of the first class III D finding while 61\% were high-risk HPV-positive. This somewhat reduces the prognostic value of a combination of a class III D cytological diagnosis with high-risk HPV-positivity as an indication for an unfavourable prognosis.

\section{Conclusion}

$\nabla$

- The presented results and data objectivate and confirm the collected data and experience obtained during the investigation and management of patients with a class III D cytological diagnosis.

- The high rate of spontaneous regressions indicates that a firsttime or even second-time cytological diagnosis of low-grade and/or moderate squamous epithelial dysplasia means that affected patients should be advised carefully and followed up with regular cytology and routine clinical and colposcopic investigations.
- At this early point in time an increase in additional investigations or the referral of the patient to a dysplasia clinic with repeat cytology and additional diagnostic investigations is more likely to merely result in the patient believing herself to be ill, and would entail additional costs which are not justifiable per se.

- Therapy is only indicated if the cytological findings persist and the intervals between follow-up investigations have been sufficiently long. Therapy, performed after colposcopic localisation, will depend on the patient's age, the wish of the patient to have children, and the type of lesion (CIN 2+). The risk of squamous cell carcinoma developing within a very short time after initial cytology is statistically very low $(<1 \%)$.

- The high negative predictive value of high-risk HPV-testing (particularly for CIN 3 lesions), depending on patient age, qualifies a first-time cytomorphological diagnosis of lowgrade or moderate dysplasia, but does not invalidate it.

- Additional high-risk HPV-testing in patients with a first-time class III D cytological diagnosis does not improve the prognostic validity for individual patients.

\section{Conflict of Interest}

$\nabla$

None.

\section{References}

1 Reagan JW, Seidemann IL, Sarcusa Y. The cellular morphology of carcinoma in situ and dysplasia or atypical hyperplasia of the uterine cervix. Cancer 1953; 6: 224-235

2 Richart RM. Natural history of cervical intraepithelial neoplasia. Clin Obstet Gynecol 1967; 10: 748-784

3 Wagner D. Münchner Nomenklatur II für die gynäkologische Zytodiagnostik. Acta Cytol 1990; 34: 900-902

4 Böhmer G, Petry KU, Iftner T et al. Der DNS-Nachweis humaner Papillomviren mittels Hybrid Capture ist als sekundäre Screeningmethode bei rezidivierenden atypischen Abstrichen der Befundklasse Pap IIID ungeeignet. Zentralbl Gynakol 2002; 124: 111-115

5 Gullota G, Margariti PA, Rabitti C et al. Cytology, histology, and colposcopy in the diagnosis of neoplastic non-invasive epithelial lesions of the cervix. Eur J Gynecol Onc 1997; 18: 36-38

6 Hording U, Junge J, Rygaard C et al. Management of low-grade CIN: follow up or treatment? Eur J Obstet Gynecol Reprod Biol 1995; 62: 4952

7 Sadler L, Saftlas A, Wang W et al. Treatment for cervical intraepithelial neoplasia and risk of preterm delivery. Obstet Gynecol Surv 2004; 59: 698-699

8 Wentzensen N, Klug S. Früherkennung des Zervixkarzinoms: Suche nach einem Gesamtkonzept. Deutsches Ärzteblatt 2008; 105: 617-622

9 Böcking A, Motherby H. Abklärung zervikaler Dysplasien mittels DNABild-Zytometrie. Pathologe 1999; 20: 25-33

10 Rörig M. Die Differenzierung der zytologischen Papanicolaou IIID und III-Befunde. Inaurugal-Dissertation, Tübingen 1986

11 Rummel HH, Frick R, Heberling D et al. Verlaufskontrolle bei Patientinnen mit suspekter Zytologie (Papanicolaou IIID). Geburtsh Frauenheilk 1977; 37: 521-526

12 Sander H, Kattner W, Soost HJ. Die zytologische Diagnose einer Dysplasie leichten und mittleren Grades. Geburtsh Frauenheilk 1978; 38: 726-734

13 Raab S. Diagnostic accuracy in cytopathology. Diagnostic Cytopathology 1993; 10: 68-75

14 Soost HJ, Baur S. Gynäkologische Zytodiagnostik. 5. Aufl. Stuttgart, New York: Thieme; 1990

15 Bland JM, Altman DG. Statistics notes: the odds ratio. BMJ 2000; 320: 1468

16 Held $U$. Was ist eine "Odds Ratio" - und wann wird sie verwendet? Schweiz Med Forum 2010; 10: 634-635 
17 Sauerbrei W, Blettner M. Interpretation der Ergebnisse von 2×2-Tafeln: Teil 9 der Serie zur Bewertung wissenschaftlicher Publikationen. Dtsch Arztebl Int 2009; 106: 795-800

18 Elit LM. Pitfalls in the diagnosis of cervical intraepithelial neoplasia 1. J Lower Genital Tract Dis 2004; 8: 181-187

19 Östör AG. Natural history of cervical intraepithelial neoplasia: a critical review. Int J Gynecol Pathol 1993; 12: 186-192

$20 \mathrm{Breinl} \mathrm{H.} \mathrm{Zytologie} \mathrm{des} \mathrm{Zervixkarzinoms} \mathrm{und} \mathrm{seiner} \mathrm{Vorstadien.} \mathrm{15.} \mathrm{For-}$ tbildungstagung für klinische Zytologie. München; 26.-30 November 1999

21 Schenck U. IIID- und IVa-Befunde: Aspekte zu Verlauf und Patientenmanagement. 20. Fortbildungstagung Klinische Zytologie. München; 2009

22 Stoler MH, Vichnin MD, Ferenczy A et al. The accuracy of colposcopic biopsy: analyses from the placebo arm of the Gardasil clinical trials. Int J Cancer 2011; 128: 1354-1362

23 Zuchna C, Hager M, Tringler B et al. Diagnostic accuracy of guided cervical biopsies: a prospective multicenter study comparing the histopathology of simultaneous biopsy and cone specimen. Am J Obst Gyn 2010; 203: 321.e1-321.e6
24 Kyrgiou M, Koliopoulous G, Martin-Wirsch P et al. Obstetric outcomes after conservative treatment for intraepithelial or early invasive cervical lesions: systematic review and meta-analysis. Lancet 2006; 367: 489-498

25 Sadler L, Saftlas A, Wang $W$ et al. Treatment for cervical intraepithelial neoplasia and risk of preterm delivery. Obstet Gynecol Surv 2004; 59: 698-699

26 Ikenberg H. HPV-Nachweis zur Triage bei auffälligen zytologischen Befunden. Gynäkologe 2003; 36: 297-304

27 Schneider A, Zahm DM, Kirchmayr $R$ et al. Screening for cervical intraepithelial neoplasia grade 2/3: validity of cytologic study, cervicography, and human papillomavirus detection. Am J Obstet Gynecol 1996; 174: $1534-1541$

28 Schiffmann M, Wentzensen $N$, Wacholder $S$ et al. Human papillomavirus testing in the prevention of cervical cancer. J Natl Cancer Inst 2011; 103: 368-383

29 Petry KU, Menton S, Menton $M$ et al. Inclusion of HPV-testing in routine cervical cancer screening for women above 29 years in Germany: Results for 8466 patients. Br J Cancer 2003; 88: 1570-1577

Deutschsprachige Zusatzinformationen online abrufbar unter: www.thieme-connect.de/ejournals/toc/gebfra. 